\title{
Self-Lubricating Polytetrafluoroethylene/Polyimide Blends Reinforced with Zinc Oxide Nanoparticles
}

\author{
Liwen Mu, ${ }^{1,2}$ Jiahua Zhu, ${ }^{2}$ Jingdeng Fan, ${ }^{1}$ Zhongxin Zhou, ${ }^{1}$ Yijun Shi, ${ }^{3}$ Xin Feng, \\ Huaiyuan Wang, ${ }^{5}$ and Xiaohua $\mathrm{Lu}^{4}$ \\ ${ }^{1}$ School of Materials Engineering, Nanjing Institute of Technology, Nanjing, Jiangsu 211167, China \\ ${ }^{2}$ Intelligent Composites Laboratory, Department of Chemical and Biomolecular Engineering, The University of Akron, \\ Akron, OH 44325, USA \\ ${ }^{3}$ Division of Machine Elements, Luleå University of Technology, 97187 Luleå, Sweden \\ ${ }^{4}$ State Key Laboratory of Materials-oriented Chemical Engineering, Nanjing University of Technology, Nanjing, \\ Jiangsu 210009, China \\ ${ }^{5}$ College of Chemistry and Chemical Engineering, Northeast Petroleum University, Daqing, Heilongjiang 163318, China
}

\begin{abstract}
Correspondence should be addressed to Liwen Mu; fujin.1234@163.com, Jiahua Zhu; jzhu1@uakron.edu, and Xin Feng; xfeng@njtech.edu.cn
\end{abstract}

Received 30 August 2015; Accepted 12 November 2015

Academic Editor: Margarida Amaral

Copyright (C) 2015 Liwen Mu et al. This is an open access article distributed under the Creative Commons Attribution License, which permits unrestricted use, distribution, and reproduction in any medium, provided the original work is properly cited.

$\mathrm{ZnO}$ nanoparticle reinforced polytetrafluoroethylene/polyimide (PTFE/PI) nanocomposites were prepared and their corresponding tribological and mechanical properties were studied in this work. The influences of ZnO loading, sliding load, and velocity on the tribological properties of $\mathrm{ZnO} / \mathrm{PTFE} / \mathrm{PI}$ nanocomposites were systematically investigated. Results reveal that nanocomposites reinforced with $3 \mathrm{wt} \% \mathrm{ZnO}$ exhibit the optimal tribological and mechanical properties. Specifically, the wear loss decreased by $20 \%$ after incorporating $3 \mathrm{wt} \% \mathrm{ZnO}$ compared to unfilled PTFE/PI. Meanwhile, the impact strength, tensile strength, and elongationat-break of $3 \mathrm{wt} \% \mathrm{ZnO} / \mathrm{PTFE} / \mathrm{PI}$ nanocomposite are enhanced by 85,5 , and $10 \%$ compared to pure PTFE/PI blend. Microstructure investigation reveals that $\mathrm{ZnO}$ nanoparticles facilitate the formation of continuous, uniform, and smooth transfer film and thus reduce the adhesive wear of PTFE/PI

\section{Introduction}

Lubrication is critical to the operational safety and reliability of industrial manufacturing and processing. Lubrication technology has been widely used in industrial applications, including roller bearings, journal bearings, and gears. Efficient lubrication is valuable to dissipate frictional heat, extend fatigue life, and reduce friction and wear [1]. Existing lubrication systems rely on the use of synthetic lubrication oil or mineral oil, which cannot be used in strictly regulated fields such as pharmaceutical, food, and health care industries due to the potential product contamination [2]. Solid lubricants are considered the best option to control friction and wear if the usage of liquid lubricants is not allowed. However, solid lubricants should meet certain requirements in practical applications, such as mechanical strength, stiffness, fatigue life, thermal expansion, and damping [3].

Polymers are extensively used as solid lubricants in dynamic mechanical parts due to their unique properties such as high strength, light weight and excellent wear, and solvent resistance [4]. Polytetrafluoroethylene (PTFE), also named "teflon," is well known for its extremely low friction coefficient and excellent chemical resistance $[5,6]$. However, the major drawbacks of PTFE, poor wear resistance and severe creep deformation, restrict its wide use in practical applications. Therefore, fibrous fillers (glass fiber, carbon fiber, and whisker) [7-9] and spherical nanoparticles [10] are added in PTFE to improve the wear resistance. PTFE has also been demonstrated as effective filler in other polymers to improve the tribological property of the polymer blends $[11,12]$. 
Polyimide (PI), a class of high performance engineering plastics, is well known for its excellent mechanical properties and stability at high temperature, as well as superior dielectric properties and good chemical resistance, which have found wide applications in aerospace, automobile, and microelectronics industry [13]. However, the intrinsic large friction coefficient and high wear rate of pure PI limit its use in dynamic motion systems $[11,14]$. Tremendous efforts have been devoted to reduce the friction coefficient and wear rate of PI by means of incorporating fibers $[4,15]$, nanometer particles [16, 17], solid lubricant [18], and so forth.

Zinc oxide $(\mathrm{ZnO})$, with outstanding mechanical properties [19], has been widely used as reinforcing filler in various polymers, including PTFE [20], polymethylmethacrylate (PMMA) [21], ultrahigh molecular weight polyethylene (UHMWPE) [22], polyetheretherketone (PEEK) [23], and polyurethane (PU) [24]. Li et al. [20] reported that the wear volume loss of $15 \mathrm{vol} . \% \mathrm{ZnO} / \mathrm{PTFE}$ is only $1 \%$ compared to pure PTFE. Chang et al. [22] found that $10 \mathrm{wt} \% \mathrm{ZnO}$ nanoparticles filled in UHMWPE reach the optimal tribological and mechanical properties of the composites with 30\% and 190\% enhancement in wear resistance and compressive strength, respectively, as compared to the pure UHMWPE.

To the best of our knowledge, the effect of $\mathrm{ZnO}$ nanoparticles on the tribological and mechanical properties of PI based nanocomposites has rarely been studied. In this work, PTFE/PI blend polymer was reinforced by different loadings of $\mathrm{ZnO}$ nanoparticles. The optimal loading was explored in association with greatest tribological and mechanical properties. The microstructures of the worn surface, transfer film, and impact-fractured surface were also examined to understand the reinforcing effect of $\mathrm{ZnO}$ in the nanocomposites.

\section{Experimental}

2.1. Materials. Polyimide powder (YS-20, 1-10 $\mu \mathrm{m}$ ) was purchased from Shanghai Research Institute of Synthetic Resins. PTFE was commercially obtained from DuPont (7A-J, $25 \mu \mathrm{m}$ commercial product). The $\mathrm{ZnO}$ nanoparticles (average diameter $\leq 60 \mathrm{~nm}$ ) are purchased from Nanjing Haitai nano materials Co. Ltd. Before use, all the materials were dried at $110^{\circ} \mathrm{C}$ for at least 6 hours in oven.

2.2. Preparation of PTFE/PI Composites. In this work, the mass fraction of PTFE in polymer blend is fixed at $15 \mathrm{wt} \%$. $\mathrm{ZnO}$ nanoparticles were added into the PTFE/PI blend with different mass ratios: $1,2,3,5,8$, and $12 \mathrm{wt} \%$, respectively. The mixture is weighted accordingly and blended mechanically. Then, the powder mixture was compressed under the pressure of $20.0 \mathrm{MPa}$ and heated to $365^{\circ} \mathrm{C}$ in a mold with heating rate of $8^{\circ} \mathrm{C} / \mathrm{min}$. The compressed composite was held at $365^{\circ} \mathrm{C}$ for $45 \mathrm{~min}$ and then cooled down to ambient temperature in the mold while keeping the pressure unchanged. For friction and wear tests, the block was cut into a ring-shaped sample with $26.0 \mathrm{~mm}$ outer diameter, $22.0 \mathrm{~mm}$ inner diameter, and $2.5 \sim 3.0 \mathrm{~mm}$ in shoulder height, as seen in Figure 1(c).
2.3. Tribological Tests and Characterization. The friction and wear tests were conducted with a ring-on-ring friction configuration, Figure 1(a). The counter-face material is AISI1045 steel with hardness of HRC 52, Figure 1(b). Sliding was performed under ambient dry friction conditions over a period of 1 hour at sliding velocity of 0.69 (550 rpm) or $1.4 \mathrm{~m} / \mathrm{s}(1115 \mathrm{rpm})$ and load of $100 \mathrm{~N}$ or $200 \mathrm{~N}$. The ambient temperature is controlled at $25^{\circ} \mathrm{C}$ and relative humidity at $50 \pm 5 \%$. Before test, the surfaces of each specimen and counterpart ring were polished to 800-grit finish with surface roughness $R_{a}$ of $0.2 \sim 0.4 \mu \mathrm{m}$ and then cleaned with alcohol. The friction force was measured using a torque shaft fixed with strain gauges, and the friction coefficient was calculated from the friction force. At the end of each test, the wear volume loss was calculated from the weight loss of each specimen. Three duplicate tests were carried out to minimize the data scattering, and the average of the data was reported.

The morphology of worn surface and impact-fractured surfaces of the composites was characterized by scanning electron microscope (SEM, QUANTA-200). The transfer films on the steel ring were examined by optical microscope.

2.4. Mechanical Tests. The tensile tests were carried out on a Universal Tester (Model CMT4254) at room temperature. The deformation rate was $5 \mathrm{~mm} / \mathrm{min}$. The impact tests were performed on an impact test machine (Model XJJ5). Impact and tensile tests were conducted according to Chinese National Standard GB/T16420-1996 and GB/T164211996, respectively. For tensile test sample preparation, each composition was molded into a narrow-waisted dumbbellshaped specimen, and the size of the narrow part is $30 \times$ $5 \times 3 \mathrm{~mm}$. For impact test, unnotched specimens with dimensions of $40 \times 3 \times 2 \mathrm{~mm}$ (with the distance of support of $20 \mathrm{~mm}$ ) were fractured by the impact mass at a speed of $2.9 \mathrm{~m} / \mathrm{s}$ and impact input energy of $1.0 \mathrm{~J}$. All the reported values were average of five effective measures.

\section{Results and Discussion}

3.1. Tribological Properties. Figure 2 shows the wear volume loss and friction coefficient of $\mathrm{ZnO} / \mathrm{PTFE} / \mathrm{PI}$ nanocomposites as a function of $\mathrm{ZnO}$ loading at $100 \mathrm{~N}$ load and sliding speed of $1.4 \mathrm{~m} / \mathrm{s}$. With increasing $\mathrm{ZnO}$ loading, both wear volume loss and friction coefficient decrease and reach the minimum value at $3 \mathrm{wt} \%$ and continuously goes up afterwards. Specifically, the wear volume loss of the nanocomposites reinforced with $3 \mathrm{wt} \% \mathrm{ZnO}$ is $20 \%$ less than that of the PTFE/PI blend polymer. This loading effect is consistent with most of the literature reports that an appropriate loading of nanomaterials leads to optimized performance $[25,26]$. In this work, $\mathrm{ZnO}$ can be well dispersed and completely covered by surrounding polymers at relatively lower loadings, for example, $3 \mathrm{wt} \%$. With further increasing $\mathrm{ZnO}$ loading, polymer chains are not sufficient enough to cover the extremely large surface area exposed by $\mathrm{ZnO}$ nanoparticles and thus nanoparticles tend to agglomerate and negatively affect the interfacial bonding 

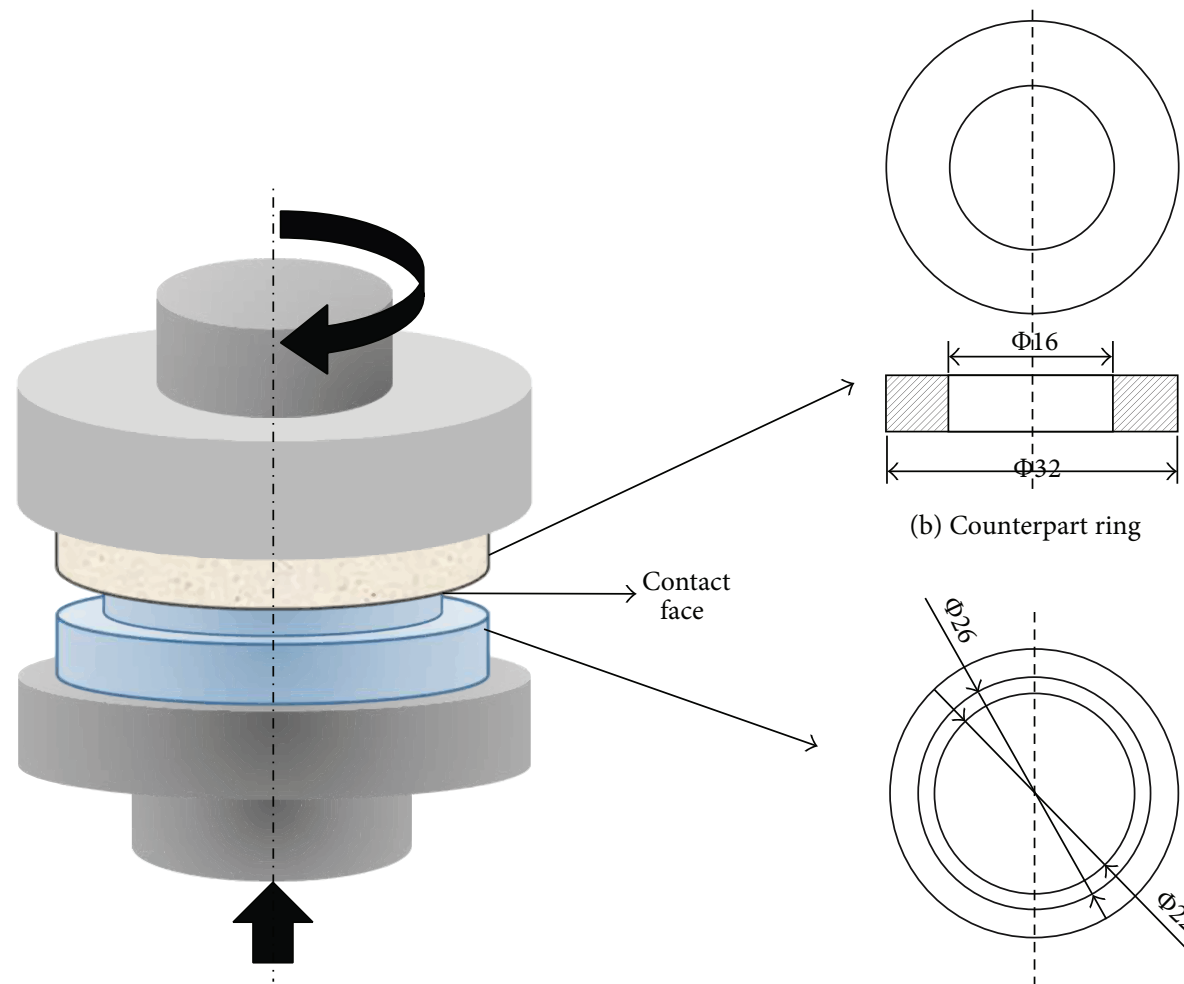

(b) Counterpart ring

(a) Ring on ring contact

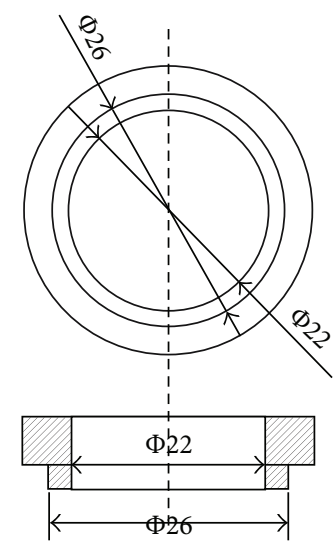

(c) Sample ring

FIGURE 1: The schematic diagram of tribological testing configuration.

with polymer matrix. The weak interfacial bonding becomes weak joint, which can be easily peeled off and thus worse tribological property was observed. Similar phenomenon was also reported in carbon nanofiber/PTFE/PI nanocomposites [27].

The effects of sliding speed on wear volume loss and friction coefficient of various specimens at a load of $200 \mathrm{~N}$ are shown in Figures 3 and 4, respectively. It can be seen that the variation of both wear volume loss and friction coefficient experiences the same trend under sliding speeds of 0.69 and $1.4 \mathrm{~m} / \mathrm{s}$. The wear volume loss of $\mathrm{ZnO} / \mathrm{PTFE} / \mathrm{PI}$ nanocomposites decreases to the minimum value and then increases afterwards. The lowest wear loss is achieved with $3 \mathrm{wt} \% \mathrm{ZnO}$ loading at higher sliding speed of $1.4 \mathrm{~m} / \mathrm{s}$, while larger $\mathrm{ZnO}$ loading of $8 \mathrm{wt} \%$ is required to reach the minimum value at relatively lower speed of $0.69 \mathrm{~m} / \mathrm{s}$. The $\mathrm{ZnO}$ nanoparticles serve as rolling balls between the friction interfaces, which would definitely reduce the interfacial friction and improve the tribological properties [23]. At higher sliding speed, larger shear force and friction energy facilitate the "pulling-off" of $\mathrm{ZnO}$ nanoparticles from polymer matrix and accumulation at the interface. Therefore, optimal amount of "rolling" $\mathrm{ZnO}$ nanoparticles would be accumulated at the interface from the nanocomposites with relatively lower $\mathrm{ZnO}$ loadings [27].

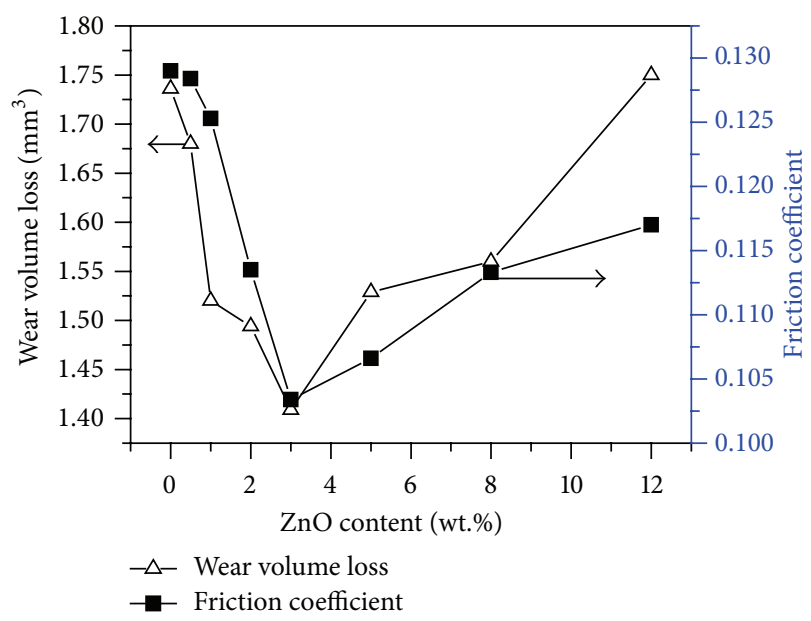

FIGURE 2: Effect of $\mathrm{ZnO}$ loading on wear volume loss and friction coefficient. Load: $100 \mathrm{~N}$; sliding speed: $1.4 \mathrm{~m} / \mathrm{s}$.

Generally, the friction coefficient decreases with increasing $\mathrm{ZnO}$ loading, Figure 4. Moreover, significantly lower friction coefficient is observed at higher sliding speed. At $1.4 \mathrm{~m} / \mathrm{s}$, more friction heat is generated at the sliding surface, 


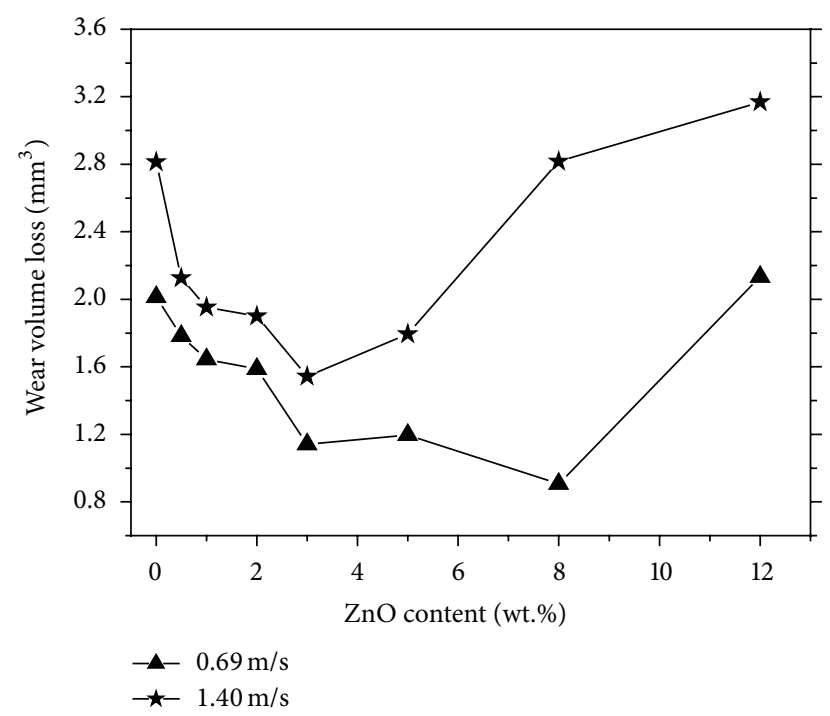

Figure 3: Wear volume loss with $\mathrm{ZnO}$ loading at 1.4 and $0.69 \mathrm{~m} / \mathrm{s}$. Load: $200 \mathrm{~N}$.

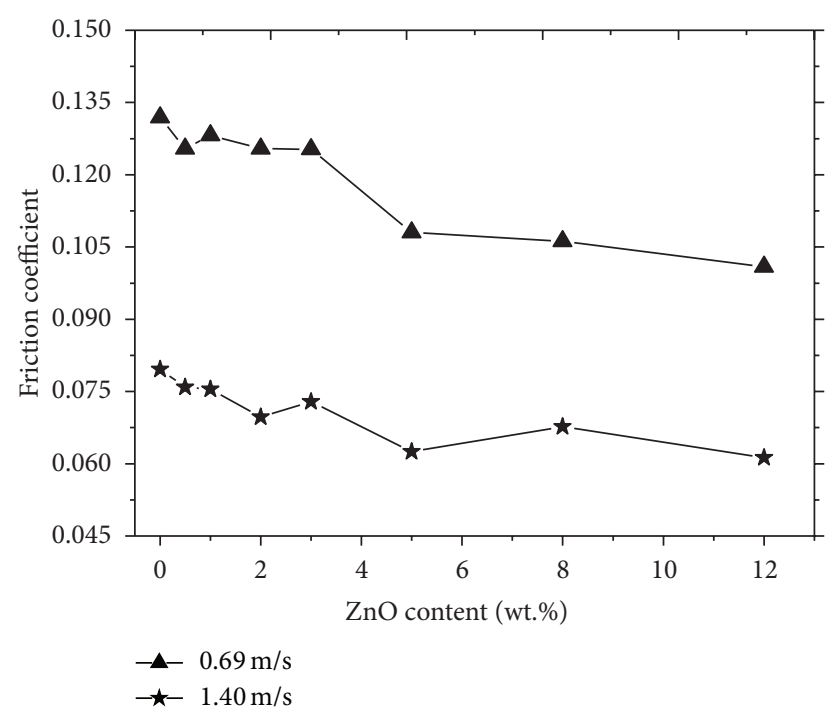

FIgURE 4: Friction coefficient with $\mathrm{ZnO}$ loading at 1.4 and $0.69 \mathrm{~m} / \mathrm{s}$. Load: $200 \mathrm{~N}$.

which raises up the contact surface temperature and causes the "softening" of polymer chains. By further accumulation of friction heat, micromelting occurs that switches plastic polymer chain into elastoplastic which facilitates the reduction of friction coefficient [28].

To explore the role of $\mathrm{ZnO}$ on friction and wear behaviors of $\mathrm{ZnO} / \mathrm{PTFE} / \mathrm{PI}$ nanocomposites, the worn surfaces and transfer films of PTFE/PI, $3 \mathrm{wt} \% \mathrm{ZnO} / \mathrm{PTFE} / \mathrm{PI}$, and $12 \mathrm{wt} \%$ $\mathrm{ZnO} / \mathrm{PTFE} / \mathrm{PI}$ composites were comparatively investigated by SEM and optical microscope, Figures 5 and 6.

In Figure 5(a), the worn surface of PTFE/PI shows obvious nicks, shallow furrows, and plastic deformation, which indicates the dominant adhesive wear behavior [11]. After incorporating $3 \mathrm{wt} \% \mathrm{ZnO}$, antiplough and anticut capacities of PTFE/PI composites can be significantly improved, Figure 5(b). Further increasing $\mathrm{ZnO}$ loading to $12 \mathrm{wt} \%$ peeled debris and deep furrows can be observed on the worn surface, Figure 5(c). These observations are in good agreement with the tribological results obtained in Figures 2-4.

Figure 6 displays the optical micrographs of transfer films formed on the counterpart steel ring after friction test. The transfer film of PTFE/PI appears to be rough and discontinuous, Figure 6(a), which could be easily scaled off from the wear track and negatively affects the wear resistance during sliding. Apparently, the transfer film for $3 \mathrm{wt} \% \mathrm{ZnO}$ is continuous, uniform, and smooth, which is helpful to maintain a stable friction and thus the best tribological properties are obtained, Figure 6(b). When $\mathrm{ZnO}$ loading increases to $12 \mathrm{wt} \%$, the transfer film becomes nonuniform, which reveals that an excess amount of $\mathrm{ZnO}$ would hinder the formation of a smooth transfer film, in Figure 6(c). As a result, the wear volume loss was increased considerably at higher filler content. These results reveal that a suitable loading of $\mathrm{ZnO}$ in the PTFE/PI polymer blend will favor the formation of smooth and continuous transfer films and contribute to the enhanced tribological properties.

Figure 7 illustrates the roles of $\mathrm{ZnO}$ nanoparticles during friction at different loadings. "Rolling ball" effect dominates the interfacial friction at relatively lower $\mathrm{ZnO}$ loading due to the good dispersion and particle-polymer interaction, Figure 7(a). Excess amount of $\mathrm{ZnO}$ in the nanocomposites leads to severe agglomeration, which affects the integrity of the nanocomposites in bulk and damages the transfer films at the friction interface, Figure 7(b). Therefore, peeled debris has been observed on the worn surface (Figure 5(c)) and also rough and noncontinuous transfer film on counterpart ring (Figure 6(c)).

3.2. Mechanical Properties. The mechanical properties of pure PTFE/PI and $\mathrm{ZnO} / \mathrm{PTFE} / \mathrm{PI}$ composites are shown in Table 1. The impact strength, tensile strength, and elongationat-break of PTFE/PI composites increase initially with the increase of $\mathrm{ZnO}$ loading and reach the maximum value at $3 \mathrm{wt} \% \mathrm{ZnO}$ and then decrease with further increasing filler content. Compared with PTFE/PI, the impact strength, tensile strength, and elongation-at-break of the $3 \mathrm{wt} \% \mathrm{ZnO} / \mathrm{PTFE} / \mathrm{PI}$ composites are increased by 85,5 , and $10 \%$, respectively, compared to PTFE/PI blend. The results indicate that the mechanical properties of PTFE/PI composites are well consistent with the tribological properties. Similar correlations between tribological and mechanical properties were reported as well by Zhang et al. in PEEK composites [29].

Due to its high specific surface area of $\mathrm{ZnO}$, a strong interfacial interaction between $\mathrm{ZnO}$ and PTFE/PI matrix would be expected. $\mathrm{ZnO}$ is distributed uniformly in the matrix and covered with polymer chains completely when the filler content is relatively low, for example, $3 \mathrm{wt} \%$ in this work. It is well known that polymer containing a preexisting crack is a result of external stress and a small craze is often 


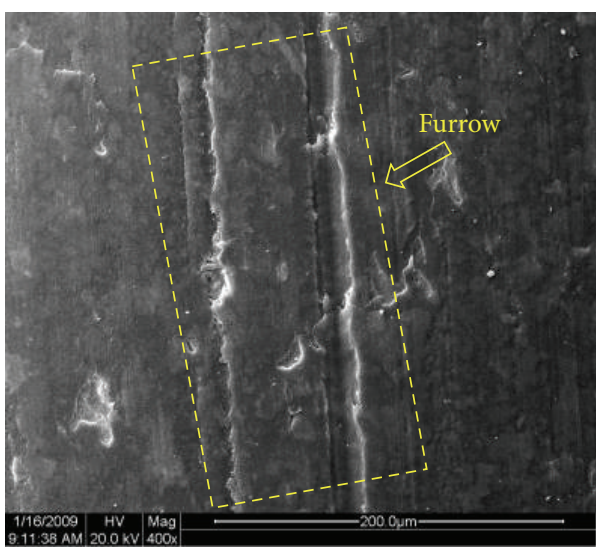

(a)

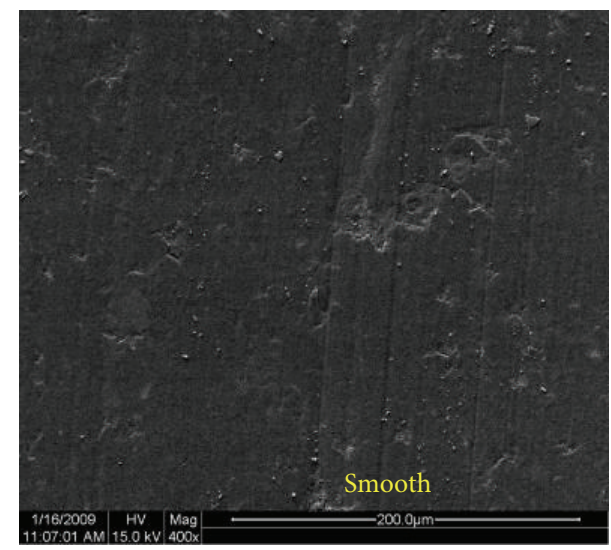

(b)

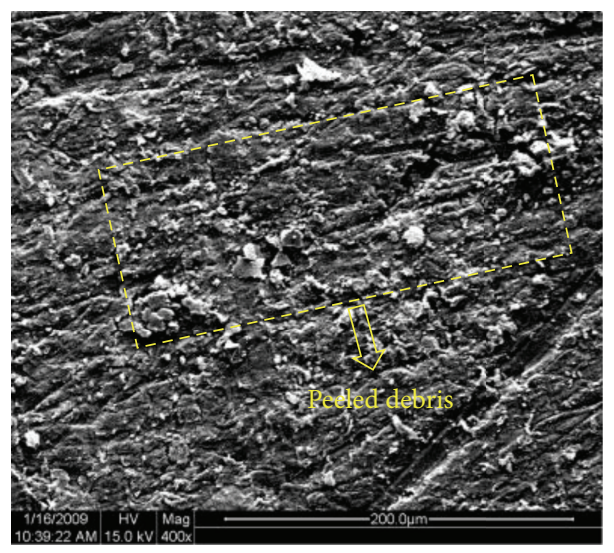

(c)

FIGURE 5: SEM micrographs of worn surfaces $(\times 400,100 \mathrm{~N}, 1.4 \mathrm{~m} / \mathrm{s})$. (a) PTFE/PI, (b) $3 \mathrm{wt} \% \mathrm{ZnO} / \mathrm{PTFE} / \mathrm{PI}$, and (c) $12 \mathrm{wt} \% \mathrm{ZnO} / \mathrm{PTFE} / \mathrm{PI}$.

TABLE 1: Mechanical properties of $\mathrm{ZnO}$ reinforced PTFE/PI nanocomposites.

\begin{tabular}{lccc}
\hline Sample & Unnotched impact strength, $\mathrm{kJ} / \mathrm{m}^{2}$ & Tensile strength, MPa & Elongation-at-break, $\%$ \\
\hline $15 \% \mathrm{PTFE} / \mathrm{PI}$ & $27.1 \pm 0.3$ & $81.7 \pm 0.5$ & $27.5 \pm 1.3$ \\
$1 \% \mathrm{ZnO} / 15 \% \mathrm{PTFE} / \mathrm{PI}$ & $35.6 \pm 0.6$ & $82.8 \pm 0.6$ & $28.2 \pm 0.5$ \\
$3 \% \mathrm{ZnO} / 15 \% \mathrm{PTFE} / \mathrm{PI}$ & $50.3 \pm 0.7$ & $85.3 \pm 0.7$ & $30.1 \pm 1.0$ \\
$8 \% \mathrm{ZnO} / 15 \% \mathrm{PTFE} / \mathrm{PI}$ & $29.3 \pm 0.7$ & $74.0 \pm 0.8$ & $20.1 \pm 1.0$ \\
\hline
\end{tabular}

formed at the tip of the crack. ZnO could serve as binder at the craze region to delay the craze growth rate. In this regard, extra energy would be required to debond $\mathrm{ZnO}$ from polymer matrix before crack further develops, which contributes to a significant improvement in tensile strength [30]. However, the interfacial bonding between PTFE/PI matrix and $\mathrm{ZnO}$ would be damaged by severely agglomerated $\mathrm{ZnO}$ in excess amount, which accounted for the poorer tensile strength of $\mathrm{ZnO} / \mathrm{PTFE} / \mathrm{PI}$ composites at larger $\mathrm{ZnO}$ loading [23].

SEM micrographs of the impact-fractured surfaces of pure PTFE/PI and $3 \mathrm{wt} \%$ and $8 \mathrm{wt} \% \mathrm{ZnO} / \mathrm{PTFE} / \mathrm{PI}$ are shown in Figures 8(a)-8(c). Obviously, the fracture surface appears relatively smooth for pure PTFE/PI but rough for $3 \mathrm{wt} \%$ and $8 \mathrm{wt} \% \mathrm{ZnO} / \mathrm{PTFE} / \mathrm{PI}$. The enhancement of impact strength can be explained by cavitation mechanism of microsized rigid particles [31], where three stages are included: stress concentration, debonding, and shear yielding. $\mathrm{ZnO}$ nanoparticles act as stress concentrators, which lead to debonding at the interface between $\mathrm{ZnO}$ and polymer matrix. Nanoparticles on the fracture surface have been considered effective evidence to support the debonding claim [32]. $\mathrm{ZnO}$ nanoparticles marked by arrows in Figures 8(b) and 8(c) clearly indicate the debonding and subsequent plastic void growth of the polymer. As shown in Figure 8(b), the voids caused by debonding can be clearly seen on the fracture surface, which absorbs large quantity of energy upon fracture, reduces stress transfer to crazing zone, and therefore enhances mechanical properties [33]. However, the increase of the voids will reduce the bond strength and the impact strength of the 


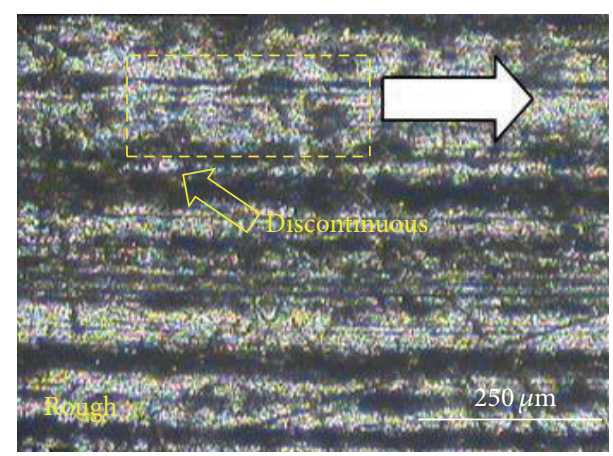

(a)

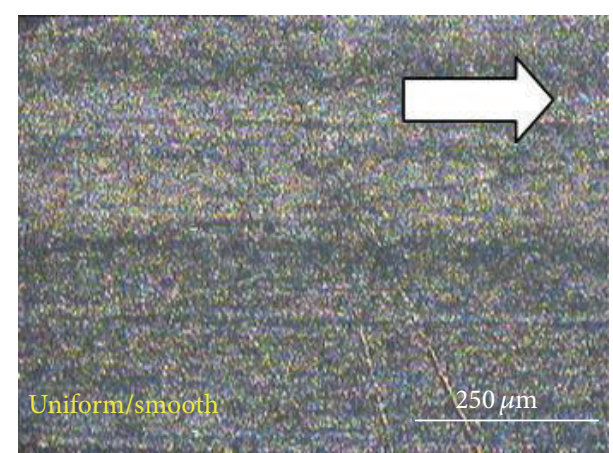

(b)

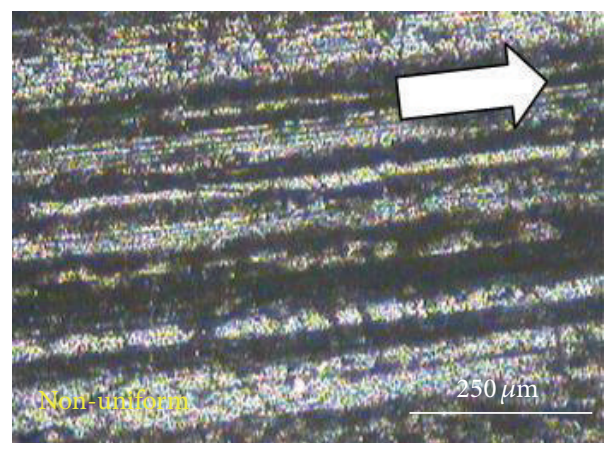

(c)

Figure 6: Optical micrographs of transfer films (×200, $100 \mathrm{~N}, 1.4 \mathrm{~m} / \mathrm{s})$. (a) PTFE/PI, (b) 3 wt $\%$ ZnO/PTFE/PI, and (c) 12 wt\% ZnO/PTFE/PI. Arrow indicates the sliding direction.

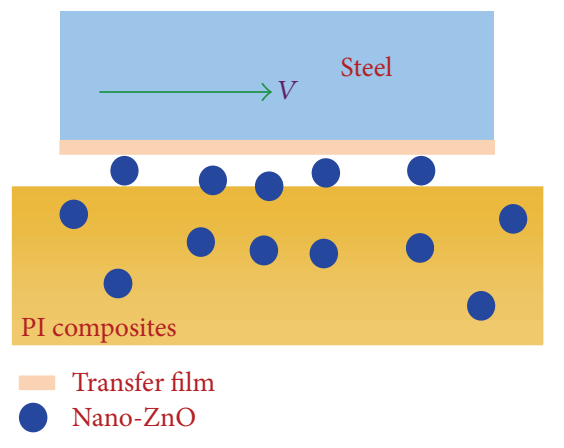

(a)

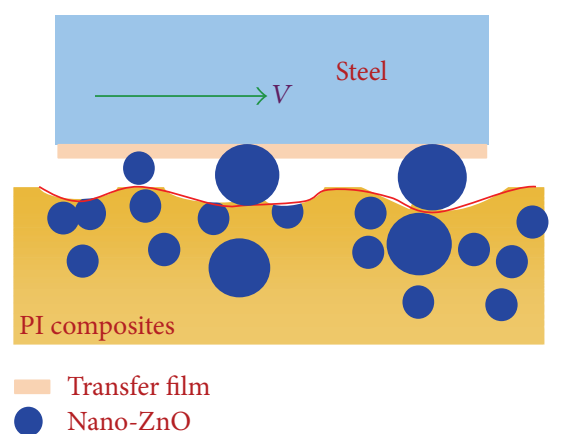

(b)

FIGURE 7: Schematic illustration of the role of $\mathrm{ZnO}$ at (a) low and (b) high loadings.

materials with the increase of $\mathrm{ZnO}$ loading, as shown in Figure 8(c).

\section{Conclusions}

To sum up, the tribological and mechanical properties $\mathrm{ZnO} / \mathrm{PTFE} / \mathrm{PI}$ composites have been investigated in this work. In comparison with unfilled PTFE/PI polymer blend, the antiwear property of $3 \mathrm{wt} \% \mathrm{ZnO} / \mathrm{PTFE} / \mathrm{PI}$ composite is increased by $20 \%$, which could be attributed to the formation of coherent, uniform transfer film that reduces the adhesive wear of PTFE/PI composites. Meanwhile, the impact strength, tensile strength, and elongation-at-break of the $3 \mathrm{wt} \% \mathrm{ZnO} / \mathrm{PTFE} / \mathrm{PI}$ nanocomposite are observed to increase by 85,5 , and $10 \%$, respectively, due to the excellent interfacial interaction between $\mathrm{ZnO}$ and PTFE/PI matrix. The achieved superior tribological and mechanical properties of the $\mathrm{ZnO} / \mathrm{PTFE} / \mathrm{PI}$ nanocomposite allow its promising tribological and mechanical applications in bearing, compressor piston rings, impeller, and so forth.

\section{Conflict of Interests}

The authors declare that there is no conflict of interests regarding the publication of this paper. 


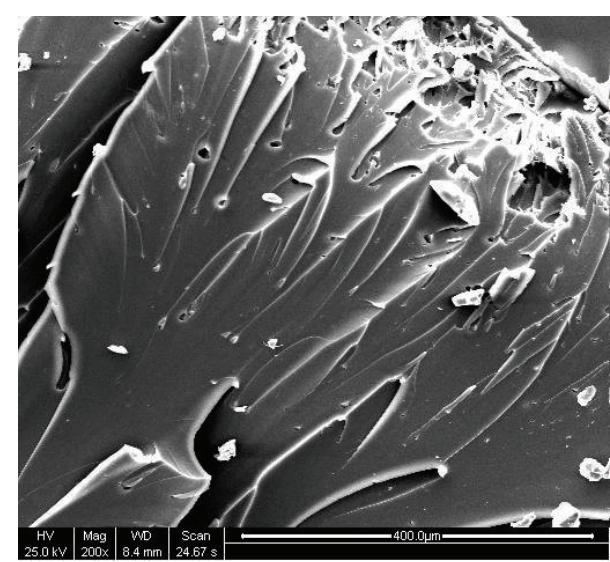

(a)

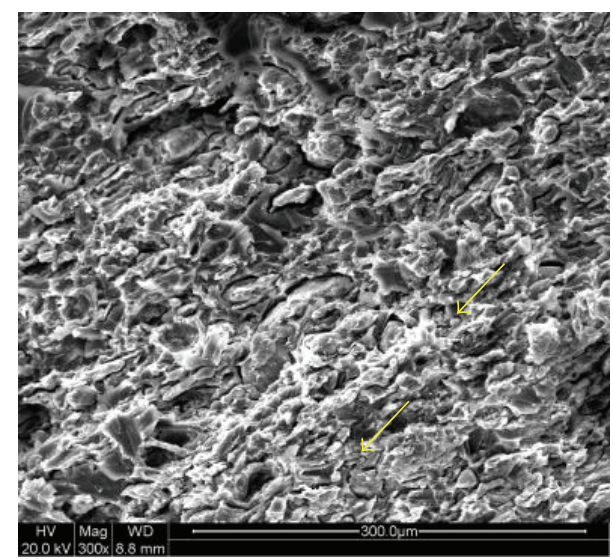

(b)

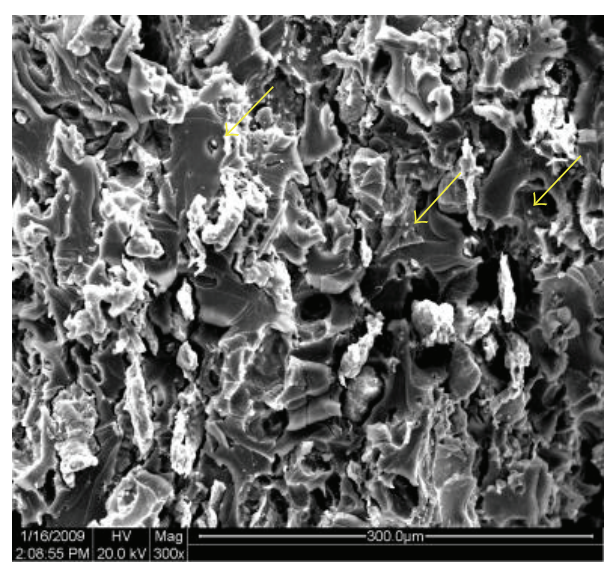

(c)

Figure 8: SEM impact-fracture surfaces. (a) PTFE/PI, (b) $3 \mathrm{wt} \% \mathrm{ZnO} / \mathrm{PTFE} / \mathrm{PI}$, and (c) $8 \mathrm{wt} \% \mathrm{ZnO} / \mathrm{PTFE} / \mathrm{PI}$. Deboned ZnO nanoparticles are marked by arrows.

\section{Acknowledgments}

The authors wish to acknowledge the support from National Basic Research Program of China (no. 2013CB733501), the Project of National Natural Science Foundation of China (no. 21176113), the Scientific Research Foundation of Nanjing Institute of Technology for the talent introduction (YKJ201309), the Scientific Research Foundation of Nanjing Institute of Technology for the innovation funds (CKJA201405), and Nanjing Institute of Technology science and technology innovation fund projects for the college students (N20150232). Partial support from the start-up fund of The University of Akron is also acknowledged.

\section{References}

[1] B. Bhushan, Modern Tribology Handbook: Materials, Coatings, and Industrial Applications, CRC Press, Boca Raton, Fla, USA, 2000.

[2] L. C. Seabra and A. M. Baptista, "Tribological behaviour of food grade polymers against stainless steel in dry sliding and with sugar," Wear, vol. 253, no. 3-4, pp. 394-402, 2002.

[3] T. W. Scharf and S. V. Prasad, "Solid lubricants: a review," Journal of Materials Science, vol. 48, no. 2, pp. 511-531, 2013.
[4] G. Zhao, I. Hussainova, M. Antonov, Q. Wang, and T. Wang, "Friction and wear of fiber reinforced polyimide composites," Wear, vol. 301, no. 1-2, pp. 122-129, 2013.

[5] X. Feng, H. Wang, Y. Shi, D. Chen, and X. Lu, "The effects of the size and content of potassium titanate whiskers on the properties of PTW/PTFE composites," Materials Science and Engineering A, vol. 448, no. 1-2, pp. 253-258, 2007.

[6] X. Feng, X. Diao, Y. Shi, H. Wang, S. Sun, and X. Lu, "A study on the friction and wear behavior of polytetrafluoroethylene filled with potassium titanate whiskers," Wear, vol. 261, no. 11-12, pp. 1208-1212, 2006.

[7] J. Zhu, Y. Shi, X. Feng, H. Wang, and X. Lu, "Prediction on tribological properties of carbon fiber and $\mathrm{TiO}_{2}$ synergistic reinforced polytetrafluoroethylene composites with artificial neural networks," Materials and Design, vol. 30, no. 4, pp. 10421049, 2009.

[8] X. H. Cheng, Y. J. Xue, and C. Y. Xie, “Tribological investigation of PTFE composite filled with lead and rare earths-modified glass fiber," Materials Letters, vol. 57, no. 16-17, pp. 2553-2557, 2003.

[9] L. Mu, J. Chen, Y. Shi et al., "Durable polytetrafluoroethylene composites in harsh environments: tribology and corrosion investigation," Journal of Applied Polymer Science, vol. 124, no. 5, pp. 4307-4314, 2012. 
[10] Y. Shi, X. Feng, H. Wang, and X. Lu, "The effect of surface modification on the friction and wear behavior of carbon nanofiber-filled PTFE composites," Wear, vol. 264, no. 11-12, pp. 934-939, 2008.

[11] Y. Shi, L. Mu, X. Feng, and X. Lu, "The tribological behavior of nanometer and micrometer $\mathrm{TiO}_{2}$ particle-filled polytetrafluoroethylene/polyimide," Materials and Design, vol. 32, no. 2, pp. 964-970, 2011.

[12] D. L. Burris and W. G. Sawyer, "A low friction and ultra low wear rate PEEK/PTFE composite," Wear, vol. 261, no. 3-4, pp. 410-418, 2006.

[13] D.-J. Liaw, K.-L. Wang, Y.-C. Huang, K.-R. Lee, J.-Y. Lai, and C.-S. Ha, "Advanced polyimide materials: syntheses, physical properties and applications," Progress in Polymer Science, vol. 37, no. 7, pp. 907-974, 2012.

[14] L. Mu, Y. Shi, X. Feng, J. Zhu, and X. Lu, "The effect of thermal conductivity and friction coefficient on the contact temperature of polyimide composites: experimental and finite element simulation," Tribology International, vol. 53, pp. 45-52, 2012.

[15] P. Samyn and G. Schoukens, "Thermochemical sliding interactions of short carbon fiber polyimide composites at high pvconditions," Materials Chemistry and Physics, vol. 115, no. 1, pp. 185-195, 2009.

[16] T. Huang, Y. Xin, T. Li et al., "Modified graphene/polyimide nanocomposites: reinforcing and tribological effects," ACS Applied Materials and Interfaces, vol. 5, no. 11, pp. 4878-4891, 2013.

[17] I. Gofman, B. Zhang, W. Zang et al., "Specific features of creep and tribological behavior of polyimide-carbon nanotubes nanocomposite films: effect of the nanotubes functionalization," Journal of Polymer Research, vol. 20, no. 10, article 258, 2013.

[18] P. Samyn, P. De Baets, and G. Schoukens, "Influence of internal lubricants (PTFE and silicon oil) in short carbon fibrereinforced polyimide composites on performance properties," Tribology Letters, vol. 36, no. 2, pp. 135-146, 2009.

[19] M. F. Omar, H. M. Akil, Z. A. Ahmad, and S. Mahmud, "The effect of loading rates and particle geometry on compressive properties of polypropylene/zinc oxide nanocomposites: experimental and numerical prediction," Polymer Composites, vol. 33, no. 1, pp. 99-108, 2012.

[20] F. Li, K.-A. Hu, J.-L. Li, and B.-Y. Zhao, "The friction and wear characteristics of nanometer $\mathrm{ZnO}$ filled polytetrafluoroethylene," Wear, vol. 249, no. 10-11, pp. 877-882, 2001.

[21] H. Chakraborty, A. Sinha, N. Mukherjee, D. Ray, and P. Protim Chattopadhyay, "A study on nanoindentation and tribological behaviour of multifunctional $\mathrm{ZnO}$ /PMMA nanocomposite," Materials Letters, vol. 93, pp. 137-140, 2013.

[22] B. P. Chang, H. M. Akil, R. B. M. Nasir, I. M. C. C. D. Bandara, and S. Rajapakse, "The effect of $\mathrm{ZnO}$ nanoparticles on the mechanical, tribological and antibacterial properties of ultra-high molecular weight polyethylene," Journal of Reinforced Plastics and Composites, vol. 33, no. 7, pp. 674-686, 2014.

[23] A. M. Díez-Pascual, C. Xu, and R. Luque, "Development and characterization of novel poly(ether ether ketone)/ZnO bionanocomposites," Journal of Materials Chemistry B, vol. 2, no. 20, pp. 3065-3078, 2014.

[24] H.-J. Song, Z.-Z. Zhang, X.-H. Men, and Z.-Z. Luo, "A study of the tribological behavior of nano-ZnO-filled polyurethane composite coatings," Wear, vol. 269, no. 1-2, pp. 79-85, 2010.

[25] J. Zhu, S. Wei, J. Ryu, L. Sun, Z. Luo, and Z. Guo, "Magnetic epoxy resin nanocomposites reinforced with core-shell structured Fe@FeO nanoparticles: fabrication and property analysis,"
ACS Applied Materials and Interfaces, vol. 2, no. 7, pp. 2100-2107, 2010.

[26] J. Zhu, S. Wei, Y. Li et al., "Surfactant-free synthesized magnetic polypropylene nanocomposites: rheological, electrical, magnetic, and thermal properties," Macromolecules, vol. 44, no. 11, pp. 4382-4391, 2011.

[27] J. Zhu, X. Feng, Y. Shi, H. Wang, and X. Lu, “Tribological and mechanical properties of carbon nanofiber-filled polytetrafluoroethylene/polyimide composites," Journal of Nanoscience and Nanotechnology, vol. 9, no. 10, pp. 5958-5965, 2009.

[28] X. Zhang, X. Pei, and Q. Wang, "Friction and wear properties of basalt fiber reinforced/ solid lubricants filled polyimide composites under different sliding conditions," Journal of Applied Polymer Science, vol. 114, no. 3, pp. 1746-1752, 2009.

[29] Z. Zhang, C. Breidt, L. Chang, and K. Friedrich, "Wear of PEEK composites related to their mechanical performances," Tribology International, vol. 37, no. 3, pp. 271-277, 2004.

[30] H. Cai, F. Y. Yan, Q. J. Xue, and W. M. Liu, "Investigation of tribological properties of $\mathrm{Al}_{2} \mathrm{O}_{3}$-polyimide nanocomposites," Polymer Testing, vol. 22, no. 8, pp. 875-882, 2003.

[31] W. C. J. Zuiderduin, C. Westzaan, J. Huétink, and R. J. Gaymans, "Toughening of polypropylene with calcium carbonate particles," Polymer, vol. 44, no. 1, pp. 261-275, 2003.

[32] D. J. Bray, P. Dittanet, F. J. Guild et al., "The modelling of the toughening of epoxy polymers via silica nanoparticles: the effects of volume fraction and particle size," Polymer, vol. 54, no. 26, pp. 7022-7032, 2013.

[33] L. Gong, B. Yin, L.-P. Li, M.-B. Yang, B.-H. Xie, and J.-M. Feng, "The morphology and mechanical properties of PP/EPDM/ nano- $\mathrm{CaCO}_{3}$ composites: effect of initial mixing state," Polymer Bulletin, vol. 70, no. 11, pp. 2935-2952, 2013. 

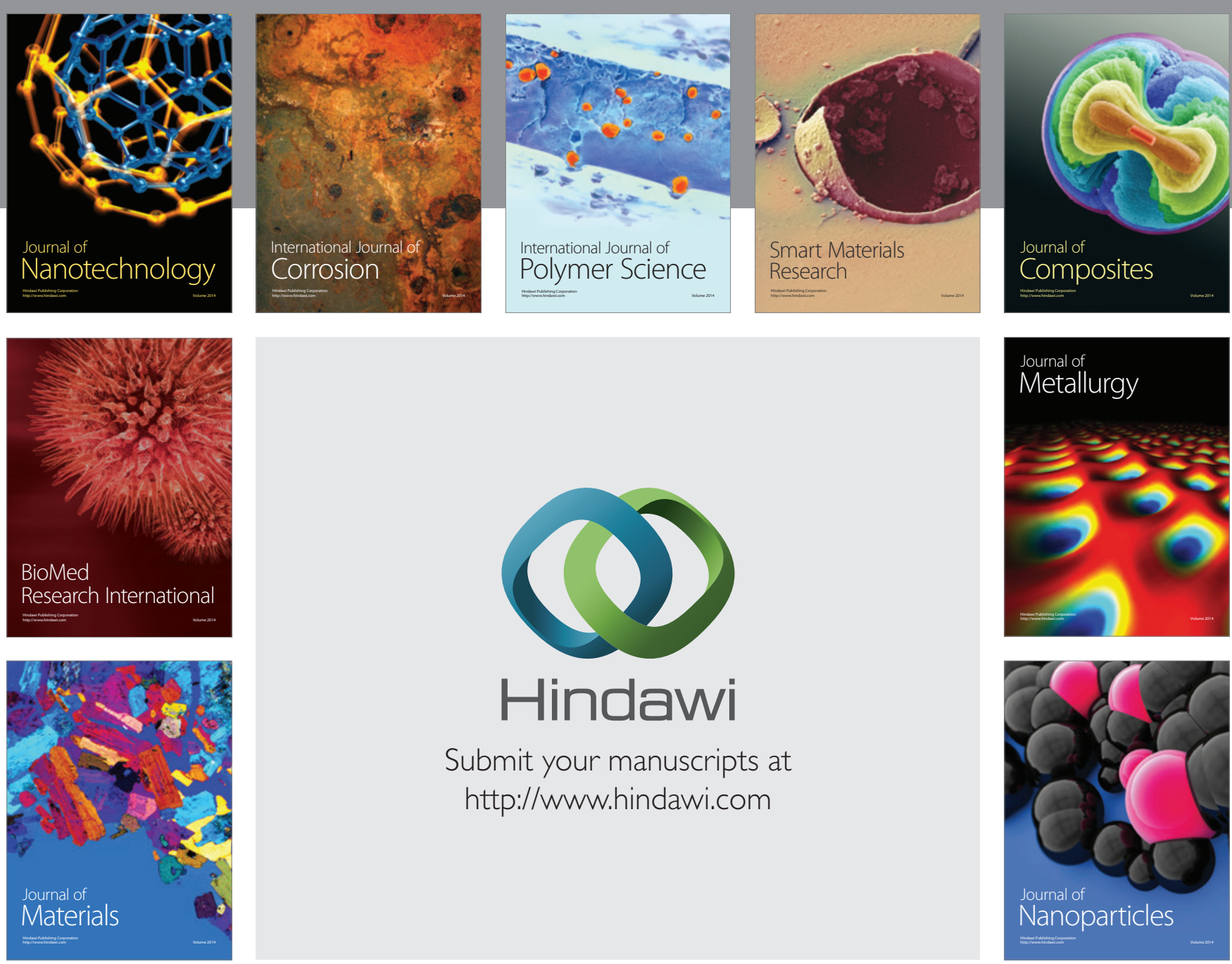

Submit your manuscripts at http://www.hindawi.com
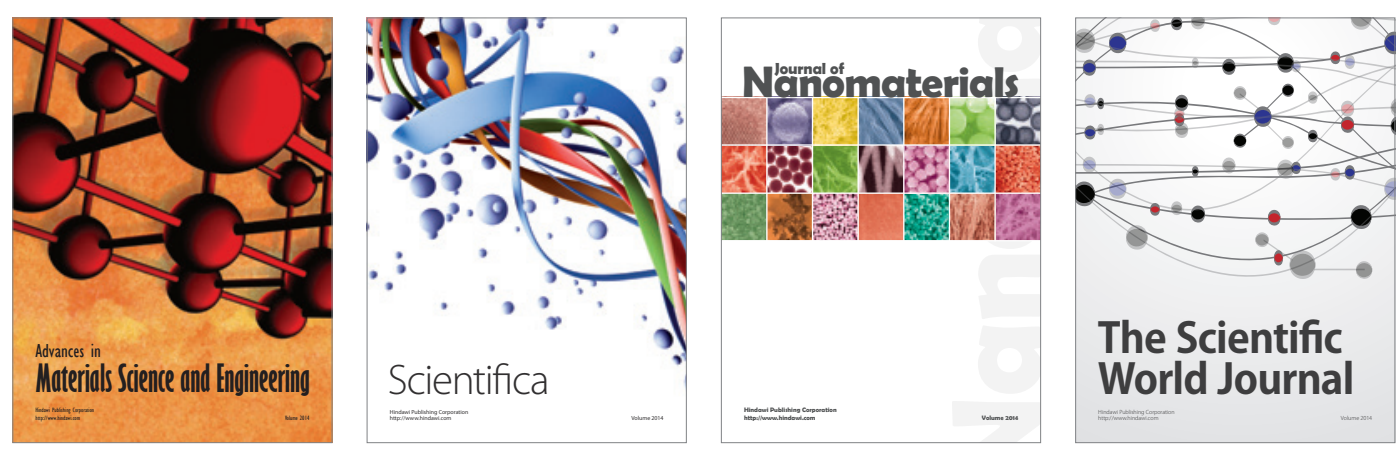

\section{The Scientific World Journal}
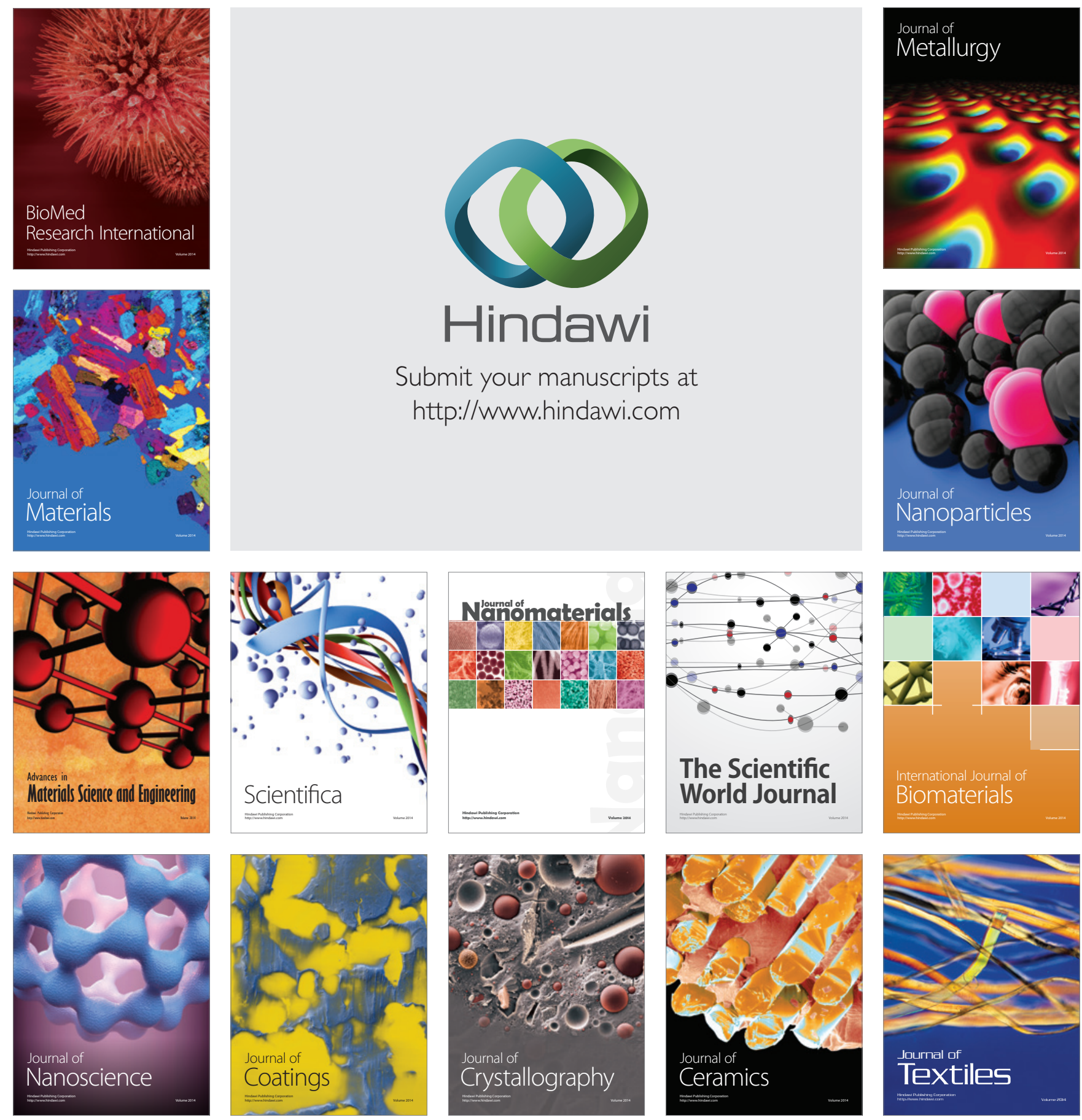